\title{
Atherosclerotic plaques induced by marble-burying behavior are stabilized by exercise training in experimental atherosclerosis.
}

\section{AUTHOR(S):}

Shimada, Kana; Mikami, Yu; Murayama, Toshinori; Yokode, Masayuki; Fujita, Masatoshi; Kita, Toru; Kishimoto, Chiharu

\section{CITATION:}

Shimada, Kana ... [et al]. Atherosclerotic plaques induced by marble-burying behavior are stabilized by exercise training in experimental atherosclerosis.. International journal of cardiology 2011, 151(3): 284-289

\section{ISSUE DATE:}

2011-09-15

URL:

http://hdl.handle.net/2433/147251

\section{RIGHT:}

(c) 2010 Elsevier Ireland Ltd.; This is not the published version. Please cite only the published version.; この論文は出版社版でありません。引 用の際には出版社版をご確認ご利用ください。 


\section{Atherosclerotic Plaques Induced by Marble-Burying Behavior Are Stabilized by Exercise Training in Experimental Atherosclerosis}

Kana Shimada, BM ; Yu Mikami, BM*; Toshinori Murayama, MD, PhD ; Masayuki Yokode, MD, PhD ; Masatoshi Fujita, MD, PhD*; Toru Kita, MD, PhD ; Chiharu Kishimoto, MD, $\mathrm{PhD}$

Departments of Cardiovascular Medicine and Human Health Sciences*, Graduate School of Medicine, Kyoto University

\section{Short title: Behavioral stress in atherosclerosis}

Supported in part by research grants from The Shimizu Foundation for the Promotion of Immunology Research, The Univers Foundation, Chiyoda Kenko Organization, The Nakatomi Foundation, and Japanese Ministry of Education, Science, and Culture (18596772). There is no conflict of interest disclosure.

Address for correspondence: Chiharu Kishimoto, M.D., Ph.D.

Department of Cardiovascular Medicine

Graduate School of Medicine, Kyoto University

54 Kawara-cho, Shogoin, Sakyo-ku, Kyoto 606-8507, Japan

Tel: (075) 751-3197, Fax: (075) 751-4281

E-mail: kkishi@kuhp.kyoto-u.ac.jp 


\begin{abstract}
Background. We assessed the hypothesis whether behavioral stress may affect the development of atherosclerosis and whether regular exercise training may influence the composition of atherosclerotic plaques in apolipoprotein (apo) E-deficient mice. Methods. Atherosclerosis was induced in apo E-deficient mice fed a high fat diet. Exercise training (45 min swimming, 3 times/week) was conducted, and behavioral stress was provoked by glass marble-burying procedure. Mice were treated with marble-burying, marble-burying behavior plus swimming training, and swimming alone over 8 weeks. Results. Exercise training decreased the atherosclerotic lesions, but marble-burying behavior increased the lesions. The plaques containing macrophage accumulation with intercellular adhesion molecule-1 (ICAM-1) expression associated with reduced collagen contents were induced in the mice treated with marble-burying. However, ICAM-1 expression was suppressed and collagen contents were reversed in the mice that received marble-burying behavior plus exercise training. In addition, exercise alone and concomitant exercise training reduced the superoxide production in aortic walls, shown by dihydroethidium staining, compared with that in mice with marble-burying behavior alone. There were no significant differences in the serum lipids profiles among the groups. Conclusions. Behavioral stress increased the atherosclerotic lesions and induced the adhesion molecule expression with superoxide production on the lesions in apo E-deficient mice. Exercise training may stabilize plaque lesions induced by marble-burying behavior in this animal model.
\end{abstract}

Keywords: atherosclerosis; exercise; behavioral stress; atherosclerotic plaques; 


\section{INTRODUCTION}

Various stresses, inducing psychological stress, are now recognized to be an important contributor to cardiovascular diseases. Both clinical and experimental evidence supports the hypothesis that behavioral stress is linked to hypertension, cardiac arrhythmias, and sudden, unexpected death [1-5]. However, the specific sites of action and mechanisms involved in the development of atherosclerosis are not well known. Inflammation, cytokine overproduction, oxidative stress, and free radicals may be considered to be key mechanisms for the development of atherosclerosis [6]. On the other hand, exercise is a deterrent of cardiovascular disease, and its antiatherogenetic effects have been described [7-9].

Defensive burying is a behavior that can be elicited in rodents in response to aversive stimuli. The term is used to describe the behavior when rats or mice bury a shock prod, noxious food or dead conspecifics under a layer of bedding material $[10,11]$. In recent years, many investigators have used the marble-burying assay as a tool for assessing axiety-like behaviors in mice [12].

In the present study, using apolipoprotein E-deficient mice, we have provided evidence for the induction of intercellular adhesion molecule-1 expression on atherosclerotic plaques by defensive burying behavior and for the suppression of the expression by exercise with the analysis of tissue superoxide production.

\section{MATERIALS AND METHODS}

\section{Experimental Atherosclerosis}

The apolipoprotein E (apo E)-deficient 129 ola $\times$ C57BL/6 hybrid mice were generous gifts of Dr. Edward M. Rubin (University of California, Berkeley, CA). These mice were mated with $\mathrm{C} 57 \mathrm{BL} / 6$ mice to produce $\mathrm{F}_{1}$ hybrids. The $\mathrm{F}_{1}$ apo $\mathrm{E}^{+/-}$mice were then backcrossed to C57BL/6 mice for 10 generations. Mice homogeneous for the apo E-null allele on a C57BL/6 background were subsequently generated. Male mice were subjected to the 
subsequent experiments. The mice were kept in a temperature-controlled facility on a 14:10-hour light-dark cycle with free access to food and water.

After being weaned at 4 weeks of age, mice were fed a normal chow diet (Oriental Yeast) until 6 weeks of age, when the animals were switched to a high fat diet containing $20 \%$ fat and $0.3 \%$ cholesterol as previously described $[13,14]$.

The experimental protocols were approved by the institutional ethics committee for animal experiments of Kyoto University.

\section{Procedure of Marble-Burying (Figure 1)}

The groups of 3 to 6 mice were placed in $23 \times 17 \times 14 \mathrm{~cm}$ cages for $30 \mathrm{~min}$. Thereafter, mice were placed individually in a $23 \times 17 \times 14 \mathrm{~cm}$ cage with 20 glass marbles, $1.5 \mathrm{~cm}$ in diameter. The glass marbles were placed in close contact in the middle of the cage on a $5 \mathrm{~cm}$ layer of sawdust. The ceiling was smooth with a few-holes so that the mice could not cling to the cage ceiling. The mice were left in the cage with marbles for $30 \mathrm{~min}$. After this, the test was terminated by removing the mice and counting the number of marbles that were more than two thirds covered by sawdust. The test was done 24 times during 8 weeks. The average value was calculated.

\section{Experimental Protocol}

At 6 weeks of age, mice were divided into 4 groups and subjected to the study protocol. They were forced to marble-burying as mentioned before and to swim a hot water bath at $37^{\circ} \mathrm{C}$ for $45 \mathrm{~min}$ per day 3 times on alternate days per week during 8 weeks as previously described [9]; control group $(n=14)$, marble-burying group $(n=20)$, marble-burying plus exercise group $(n=15)$, and exercise group $(n=7)$. It was already reported by us that this protocol of forced swimming exercise was not stressful for rodents [9]. The number of burying marbles was recorded at each time. The measurement was repeated three times at each time. At 14 weeks the mice were killed by puncture of the ventricle under ether 
anesthesia. The organs were weighed, and the ratios of organ weight to body weight were calculated.

\section{Tissue Processing}

Mice were killed by bleeding with puncture of the ventricle. The vasculature was perfused with sterile phosphate buffered saline and $6.8 \%$ sucrose. The root of the aorta was dissected under a microscope and frozen in OCT embedding medium for serial cryosectioning covering $1.0 \mathrm{~mm}$ of the root. The first section was harvested when the first cusp became visible in the lumen of the aorta. Four sections of $6 \mu \mathrm{m}$ thickness were harvested per slide, and thus 8 slides per mouse were prepared. All sections were immersed for $15 \mathrm{sec}$ in $60 \%$ isopropanol, stained for $30 \mathrm{~min}$ in a saturated oil-red-O solution at room temperature, counterstained with hematoxylin, and then mounted under coverslips with glycerol gelatin [13, 14]. Also, collagen contents were detected by Sirius red staining. The oil-red O and Sirius red stained sections were analyzed, blinded to group, as previously described [13-15].

\section{Immunohistochemistry}

Anti-macrophage (anti-M $\phi$, M 3184, 1:400, PharMigen) and anti-intercellular adhesion molecule-1(ICAM-1) (M-19, 1:100, Santa Cruz Biotechnology) antibodies were applied to acetone-fixed cryosections of aortic roots. After being washed, the sections were then exposed to second antibodies (horseradish peroxidase-conjugated antibodies), and the horseradish peroxidase-conjugated antibody binding was visualized with diaminobenzidine. Sections were counterstained with methyl green or Mayer's hemotoxylin. Macrophages in the lesions were quantitatively evaluated as previously described $[15,16]$. Data were obtained by dividing the number of positively stained cells by all counterstained cells inside the internal elastic lamina. Three to five random microscopic field were analyzed at $\times 200$. ICAM- 1 expression was qualitatively evaluated. 


\section{In Situ Defection of Superoxide Production}

To evaluate in situ superoxide production from aorta, unfixed frozen cross sections of the specimens were stained with dihydroethidium (DHE; Molecular Probe, OR) according to the previously validated method [17-19]. In the presence of superoxide, DHE is converted to the fluorescent molecule ethidium, which can then label nuclei by intercalating with DNA. Briefly, the unfixed frozen tissues were cut into $10-\mu \mathrm{m}$ thick sections, and incubated with $10 \mu \mathrm{M}$ DHE at $37^{\circ} \mathrm{C}$ for $30 \mathrm{~min}$ in a light-protected humidified chamber. The images were obtained with a laser scanning confocal microscope. Superoxide production was demonstrated by red fluorescence labeling. For quantification of ethidium fluorescence from aortas, fluorescence (intensity $\times$ area) was measured using a high-power image. The validity of DHE staining for the evaluation of superoxide production from the atherosclerotic lesions was already reported by us [19].

\section{Lipid Measurement}

Serum was separated by centrifugation and stored at $-80^{\circ} \mathrm{C}$. Serum total cholesterol (TC) and triglyceride (TG) levels were measured with assay kits (Wako) according to the manufacturer's instructions.

\section{Statistical Analysis}

Values were expressed as means \pm SD. One-way ANOVA with subsequent Fisher protected least-significant difference tests was performed. A value of $\mathrm{P}<0.05$ was considered statistically significant.

\section{RESULTS}

\section{Organ Weights (Table 1)}

There were no significant differences in body weight, heart weight, or heart weight to body weight among the groups. 


\section{Atherosclerotic Lesions (Figures 2 and 3)}

The surface areas of aortic roots covered by fatty streak lesions were quantified in oil red-O-stained samples, and specimens among the groups were compared. Controls (105.30土 $\left.39.0 \times 10^{3} \mu \mathrm{m}^{2}, \mathrm{n}=14\right)$ and the marble-burying behavior group $\left(138.06 \pm 25.74 \times 10^{3} \mu \mathrm{m}^{2}\right.$, $\mathrm{n}=20$ ) developed extensive lesions in the root of the aorta (Fig.2). Exercise group (61.62 \pm $\left.15.60 \times 10^{3} \mu \mathrm{m}^{2}, \mathrm{n}=7\right)$ showed the minimal lesions among the groups. The marble-burying behavior increased the severity of atherosclerosis significantly $(\mathrm{P}<0.05)$ compared with controls. In mice treated with marble-burying plus exercise $\left(69.42 \pm 19.50 \times 10^{3} \mu \mathrm{m}^{2}, \mathrm{n}=15\right)$, the fractional area of lesions was reduced $(\mathrm{P}<0.01)$ compared with the marble-burying group as shown in Figure 2.

Compared with the control $\left(38.22 \pm 10.14 \times 10^{3} \mu \mathrm{m}^{2}\right)$, collagen contents were decreased $(\mathrm{P}<0.05)$ by marble-burying behavior $\left(21.06 \pm 7.8 \times 10^{3} \mu \mathrm{m}^{2}\right)$ and were returned to the control levels by the treatment of marble-burying plus exercise $\left(39.78 \pm 17.94 \times 10^{3}\right.$ $\mu \mathrm{m}^{2}$ ) (Fig. 3). In exercise group $\left(46.80 \pm 10.92 \times 10^{3} \mu \mathrm{m}^{2}\right)$, collagen contents were highest among the groups.

\section{Inflammatory Cell Surface Markers (Figures 2 and 4)}

The degree of macrophage-positive cells was decreased in the exercise-treated group and the marble-burying behavior-treated plus concomitant exercise-treated group compared with the other two groups (Fig.2). The expression of ICAM-1 was increased by marble-burying behavior and was decreased by the concomitant exercise. The expression of ICAM-1 in exercise group was minimal (Fig. 4).

\section{In Situ Superoxide Production (Figure 5)}

To analyze the in situ superoxide production in the aortic wall, DHE staining was performed. Ethidium fluorescence was detected in the plaques. The intensity of DHE staining was increased by the marble-burying behavior, and was suppressed by the marble-burying 
plus swimming training group. The intensity of DHE staining in exercise group was lowest among the groups.

\section{Lipid Profiles (Table 1)}

There were no significant differences in the serum lipids profiles among the groups.

\section{Numbers of Marbles Buried (Figure 6)}

Figure 4 shows the numbers of marbles buried and the effects of exercise upon marble burying. The numbers in mice treated with exercise alone and concomitant exercise were significantly less compared with those in mice treated with marble-burying alone, which may reflect the less psychological stress-state in the exercise-treated group and the concomitant exercise-treated group.

\section{DISCUSSION}

In the current study, it was shown that (i) apo E-deficient mice fed a high fat diet over 8 weeks developed severe fatty streak lesions of aortic roots, (ii) behavioral stress increased the severity of atherosclerosis, and induced the atherosclerotic plaques with the increased ICAM-1 expression and superoxide production in aortic walls, and (iii) the propensity of the plaque unstability was reduced by the concomitant exercise treatment.

Chronic inflammation is thought to be of central importance in atherosclerosis $[6,20]$. It was shown that regular and chronic exercise could suppress overt and subclinical inflammation [21, 22], based on the fact that atherosclerosis can be considered as generalized manifestations of an inflammatory disease [6]. We and other investigators had already reported that experimental atherosclerosis in apo E-deficient mice was markedly suppressed by Fc $\gamma$ portion of immunoglobulin administration, possibly by an antiinflammatory action via inhibitory Fcy receptor IIB [15, 16, 23].

As mentioned previously, the so-called negative emotions, such as depression and anxiety, have been associated with the development of atherosclerosis and coronary artery 
disease [1-5]. Also, psychosocial distress and anxiety disorders are a significant risk factor for atherosclerosis [24-26]. Although the exact mechanisms are not yet clear, burying behavior in the mouse is provoked by glass marble, which is considered to be a kind of defensive burying [10-12].

In the present study, using the animal model of behavior stress induced by glass-burying procedure, we clearly demonstrated that behavioral stress increased the expression of adhesion molecule and superoxide production on atherosclerotic plaques, and that chronic and regular swimming training suppressed the expression of ICAM-1 and the overload of superoxide in aortic walls. It has already been established that the intensity of exercise training used in this study ameliorated the development of atherosclerosis in apo E-deficient mice [9], and that the degree of tissue DHE staining correlates with the superoxide production [17-19]. Thus, the decrease of the intensity of ethidium fluorescence expression in aortic walls may reflect the decrease of superoxide by exercise treatment.

The mechanisms by which exercise might benefit cardiovascular diseases are still unknown [7, 8]. It is reported that exercise suppresses inflammation, hypertension, and atherosclerosis [7, 8], and may reverse some cardiomyopathic conditions [27, 28]. We already reported that chronic and regular exercise reduced the experimental atherosclerosis by the antioxidant effects [9]. Indeed, in the current study, exercise reduced the lesions and might stabilize atherosclerotic plaques by reducing the expression of macrophages and ICAM-1 as well as decreased intensity of DHE. Accordingly, regular exercise might be recommended for the clinical therapy for atherosclerotic patients.

The present study also demonstrated that exposure to behavioral stress induces the overexpression of ICAM-1 and the overproduction of superoxide in the aortic walls with relatively less amount of collagen contents in apoE-deficient mice, although it did not increase the severity of atherosclerosis significantly. This phenomenon may be of significant 
clinical relevance to humans. However, it should be noted that behavioral stress has been shown to have different effects in other strains of mice $[10,11]$.

Behavioral stress is now recognized to be an important contributor to cardiovascular diseases, as mentioned before [1-5]. From the current study, however, appropriate and regular exercise may be recommended for the secondary prevention of atherosclerotic patients, especially having sustained psychological stress.

Several limitations of the present study should be mentioned. First, the present study lacked the precise evaluation of hemodynamic study. Recently, it was reported that high heart rate and vigorous shear stress may affect the development of atherosclerosis [29]. However, it was already reported that the severity of atherosclerosis was reduced by the appropriate exercise protocol $[9,30]$. Second, the present study did not demonstrate the precise and molecular mechanisms why exercise might reduce the severity of experimental atherosclerosis. Third, the present experimental findings cannot be applied to the clinical settings directly because of the species differences of sensitivity for stress or anxiety.

In conclusion, behavioral stress may induce the overexpression of ICAM-1 and superoxide overproduction in the lesions in apo E-deficient mice, and concomitant exercise training may downregulate ICAM-1 expression and superoxide production, and reversed the collagen contents, resulting in the reduction of atherosclerosis. In view of the propensity of atherosclerotic plaques having adhesion molecule overexpression and superoxide overproduction, it may be concluded that exercise training may be useful for stabilizing the atherosclerotic plaques in clinical settings. Exploration of clinical usefulness of the results might be warranted. 
Acknowledgement: The authors of this manuscript have certified that they comply with the Principles of Ethical Publishing in the International Journal of Cardiology [31]. 


\section{REFERENCES}

[1] Schwartz PJ, LaRovere MT, Vanoli E. Autonomic nervous system and sudden cardiac death: Experimental basis and clinical observations for post-myocardial infarction risk stratification. Circulation 1992; 85 (Suppl I): 177-91.

[2] Specchia G, DeServi S, Falcone C, et al. Mental arithmetic stress testing in patients with coronary artery disease. Am Heart J 1984; 108: 56-63.

[3] Kamarck T, Jennings JR. Biobehavioral factors in sudden cardiac death. Psychol Bull 1991; 109: 42-75.

[4] Chauhan A, Mullins PA, Taylor G, Petch MC, Schofield PM. Effect of hyperventilation and mental stress on coronary blood flow in syndrome X. Br Heart J 1993; 69: 516-24.

[5] Lacy CR, Contrada RJ, Robbins ML, et al. Coronary vasoconstriction induced by mental stress. Am J Cardiol 1995; 75: 503-5.

[6] Ross R. Atherosclerosis: an inflammatory disease. N Engl J Med 1999; 340: 115-26.

[7] Koller A, Shephard RJ, Balady GJ. Exercise as cardiovascular therapy. Circulation 1999; 99: $963-72$.

[8] Pynn M, Schäfer K, Konstantinides S, Halle M. Exercise training reduces neointimal growth and stabilizes vascular lesions developing after injury in apolipoprotein E-deficient mice. Circulation 2004; 109: 386-92.

[9] Okabe T, Shimada K, Hattori M, et al. Swimming reduces the severity of atherosclerosis in apolipoprotein E-deficient mice by antioxidant effects. Cardiovasc Res 2007; 74: 537-45.

[10] Broekkamp CL, Rijk HW, Joly-Gelouin D, Lloyd KL. Major tranquillizers can be distinguished from minor tranquillizers on the basis of effects on marble burying and swim-induced grooming in mice. Eur J Pharmacol 1986; 126: 223-9.

[11] Pinel JP, Gorzalka BB, Ladak F. Cadaverine and putrescine initiate the burial of dead 
conspecifics by rats. Physiol Behav 1981; 27: 819-24.

[12] Thomas A, Burant A, Bui N, Graham D, Yuva-Payer L, Paylor R. Marble burying reflects a repetitive and perseverative behavior more than novelty-induced anxiety. Psychopharmacology 2009; 204:361-73.

[13] Murayama T, Yokode M, Kataoka H, et al. Intraperitoneal administration of anti-c-fms monoclonal antibody prevents initial events of atherogenesis but does not reduce the size of advanced lesions in apolipoprotein E-deficient mice. Circulation 1999; 99: 1740-6.

[14] Okabe T, Kishimoto C, Shimada K, Murayama T, Yokode M, Kita T. Effects of MCI-186 (Edaravone), a novel free radical scavenger, upon experimental atherosclerosis in apolipoprotein E-deficient mice. Circulation J 2006; 70: 1216-9.

[15] Yuan Z, Kishimoto C, Sano H, Shioji K, Xu Y, Yokode M. Immunoglobulin treatment suppresses atherosclerosis in apolipoprotein E-deficient mice via the Fc portion. Am $\mathbf{J}$ Physiol 2003; 285: H899-H906.

[16] Shioji K, Kishimoto C, Sasayama S. Fc receptor-mediated inhibitory effect of immunoglobulin therapy on autoimmune giant cell myocarditis: concomitant suppression of the expression of dendritic cells. Circ Res 2001; 89: 540-6.

[17] Miller FJ, Gutterman DD, Rios CD, Heistad DD, Davidson BL. Superoxide production in vascular smooth muscle contributes to oxidative stress and impaired relaxation in atherosclerosis. Circ Res 1998; 82: 1298-305.

[18] Takaya T, Kawashima S, Shinohara M, et al. Angiotensin II type 1 receptor blocker telmisartan suppresses superoxide production and reduces atherosclerotic lesion formation in apolipoprotein E-deficient mice. Atherosclerosis 2006; 186: 402-10.

[19] Shimada K, Murayama T, Yokode M, et al. N-acetylcysteine reduces the severity of atheroslclerosis in apolipoprotein E-deficient mice by reducing superoxide production. Circulation 2009; 73: 1337-41. 
[20] Kondo N, Nomura M, Nakaya Y, Ito S, Ohguro T. Association of inflammatory marker and highly sensitive C-reactive protein with aerobic exercise capacity, maximum oxygen uptake and insulin resistance in healthy middle-aged volunteers. Circ J 2005; 69: 452-7.

[21] Gielen S, Adams V, Möbius-Winkler S, et al. Anti-inflammatory effects of exercise training in the skeletal muscle of patients with chronic heart failure. J Am Coll Cardiol 2003; 42: 861-8.

[22] Milani RV, Lavie CJ, Mehra MR. Reduction in C-reactive protein through cardiac rehabilitation and exercise training. J Am Coll Cardiol 2004; 43: 1056-61.

[23] Nicoletti A, Kaveri S, Caligiuri G, Bariéty J, Hansson GK. Immunoglobulin treatment reduces atherosclerosis in apo E knockout mice. J Clin Invest 1998; 102: 910-8.

[24] Paterniti S, Zureik M, Ducimetière P, Touboul PJ, Fève JM, Alpérovitch A. Sustained anxiety and 4-year progression of carotid atherosclerosis. Arterioscler Thromb Vasc Biol 2001; 21: 136-41.

[25] Todaro JF, Shen BJ, Niaura R, Spiro A IIIrd, Ward KD. Effects of negative emotions on frequency of coronary heart disease. The Normative Aging study. Am J Cardiol 2003; 92: 901-6.

[26] Lavie CJ, Milani RV. Prevalence of anxiety in coronary patients with improvement following cardiac rehabilitation and exercise training. Am J Cardiol 2004; 93: 336-9.

[27] Maloyan A, Gulick J, Glabe CG, Kayed R, Robbins J. Exercise reverses preamyloid oligomer and prolongs survival in $\alpha \mathrm{B}$-crystallin-based desmin-related cardiomyopathy. Proc Natl Acad Sci USA 2007; 104: 5995-6000.

[28] Konhilas JP, Watson PA, Maass A, et al. Exercise can prevent and reverse the severity of hypertrophic cardiomyopathy. Circ Res 2006; 98: 540-8.

[29] Giannoglou G, Chatzizisis YS, Zamboulis C, Parcharidis GE, Mikhailidis DP, Louridas GE. Elevated heart rate and atherosclerosis: An overview of the pathogenetic mechanisms. 
Int J Cardiol 2008; 126: 302-312.

[30] Matsumoto Y, Adams V, Jacob S, Mangner N, Schuler G, Linke A. Regular exercise training prevents aortic valve disease in low-density lipoprotein-receptor-deficient mice. Circulation 2010; 121: 759-767.

[31] Coats AJ. Ethical authorship and publishing. Int J Cardiol 2009; 131:149-50. 


\section{FIGURE LEGENDS}

Figure 1. Marble-burying behavior

(A) The 20 glass marbles were placed in a cage.

(B) Mice were placed individually in a cage with for $30 \mathrm{~min}$. After this, the test was terminated by removing the mice and counting the number of marbles that were covered by sawdust more than two thirds.

(C) Number of marbles buried was calculated.

Figure 2. Atherosclerotic lesions and, macrophage infiltration

The lesions (white arrows) in the marble-burying procedure plus exercise-treated mouse (C) and the exercise-treated mouse (D) were smaller and covered less of the inner circumference of the aortic root than those (black arrows) of the control mouse (A) and marble-burying procedure-treated mouse (B). Insets boxes show magnified samples for macrophages $(\mathrm{M} \phi)$ (arrow-heads).

Oil-red-O stain $(\mathrm{A}, \mathrm{B}, \mathrm{C}, \mathrm{D} \times 60)$

$* \mathrm{P}<0.05, * * \mathrm{P}<0.01$ vs Control group. \# $\mathrm{P}<0.01$ vs Marble-burying group.

Figure 3. $\underline{\text { Collagen contents }}$

Compared with the control (A), collagen contents (red area, surrounded by dashed line) were decreased by marble-burying behavior (B), and were returned to the control levels by the treatment of marble-burying plus exercise (C). In exercise group (D), collagen contents were highest. $\mathrm{P}$ indicates plaques.

Sirius red stain $(A, B, C, D \times 120)$

$* \mathrm{P}<0.05$, vs Control group. \# $\mathrm{P}<0.01$ vs Marble-burying group.

Figure 4. Intercellular adhesion molecule -1(ICAM-1) expression

The expression of ICAM-1 in the lesion (arrows) of the marble-burying plus exercise-treated mouse (C) were decreased compared with those of the control mouse (A) and marble-burying procedure-treated mouse (B). The expression of 
ICAM-1 in exercise group was minimal (D).

ICAM-1 stain $(A, B, C, D \times 100)$

Figure 5. Dihydroethidium (DHE) staining

Ethidium fluorescence was detected in the plaques (A). The intensity of DHE staining was increased by the marble-burying behavior (B), and was suppressed by the marble-burying plus swimming training group (C). The intensity of DHE staining in exercise group (D) was lowest among the group. P indicates plaques.

DHE stain $(A, B, C, D \times 120)$

${ }^{*} \mathrm{P}<0.05$, ** $\mathrm{P}<0.01$ vs Control group. \# $\mathrm{P}<0.01$ vs Marble-burying group.

Figure 6. Numbers of marbles buried

The numbers in mice treated with exercise alone and concomitant exercise were significantly less compared with those in mice treated with marble-burying alone. $* \mathrm{P}<0.05, * * \mathrm{P}<0.01$ vs Marble burying group. 
Figure 1.

(A)

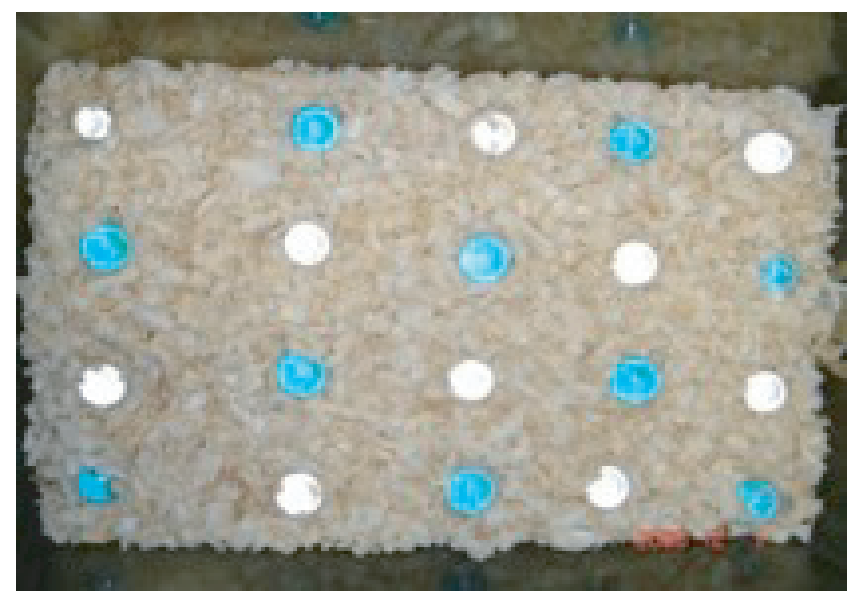

(B)

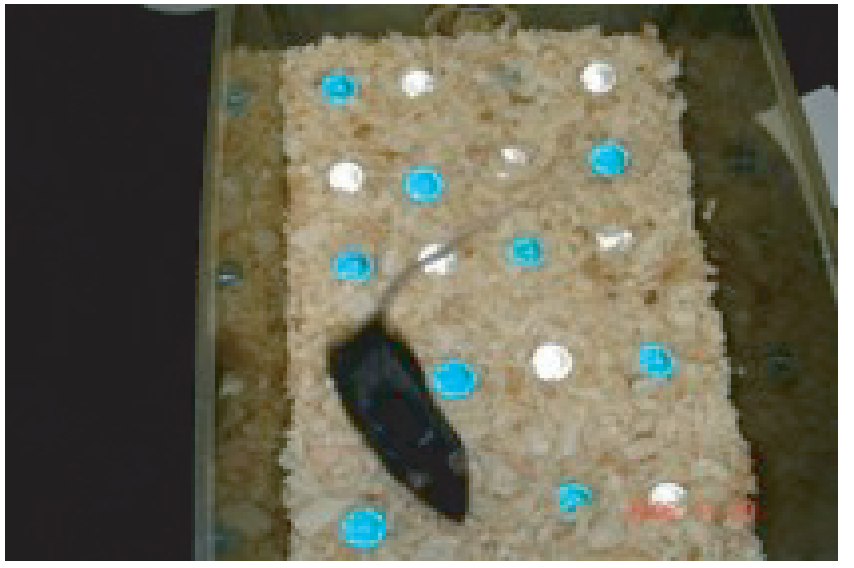

(C)

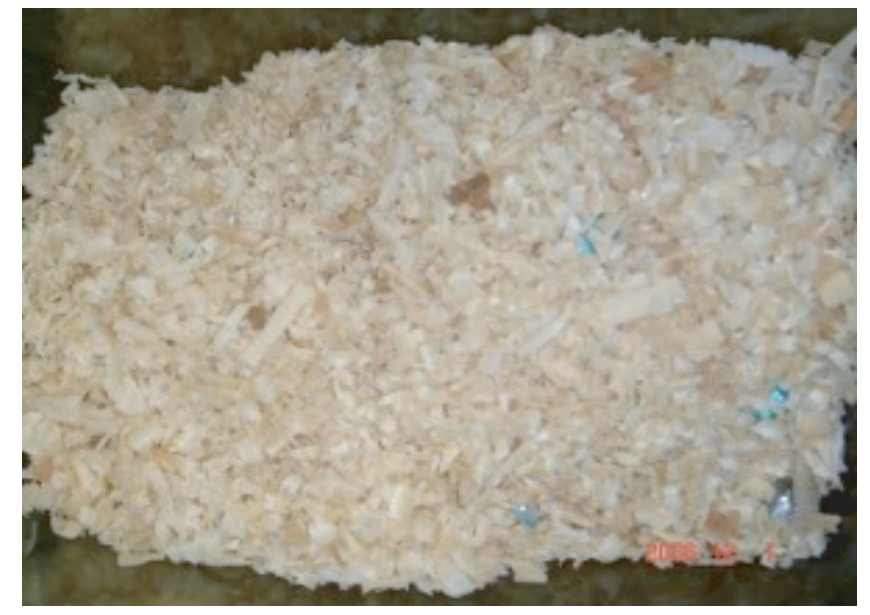


Figure 2.

(A) Control

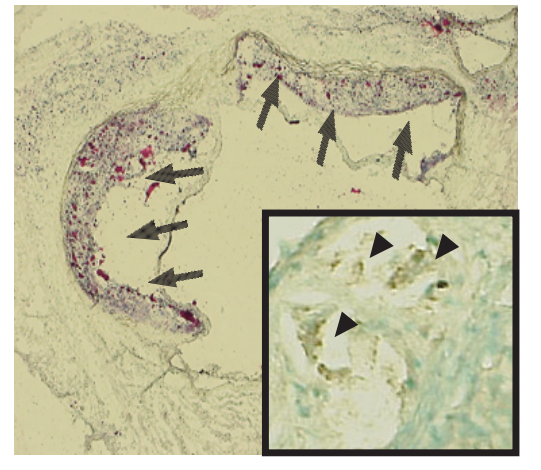

(C) Marble-burying + Exercise

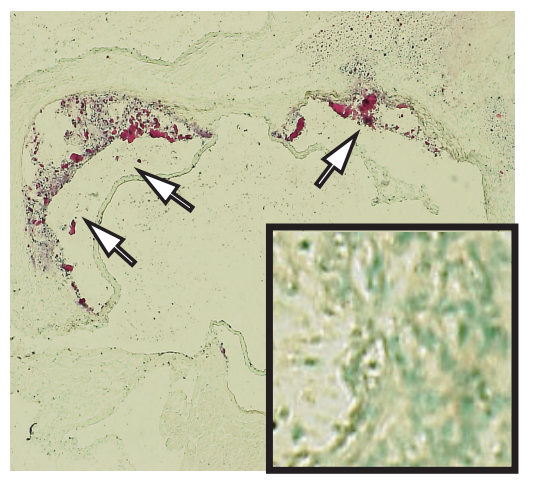

(B) Marble-burying

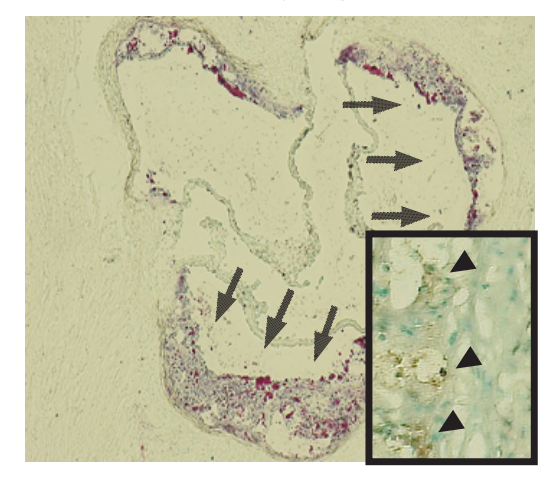

(D) Exercise

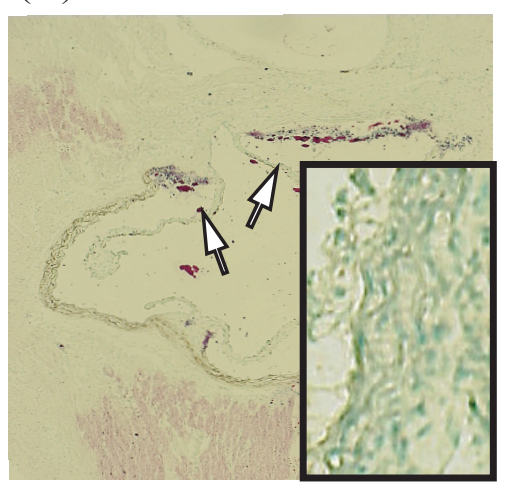

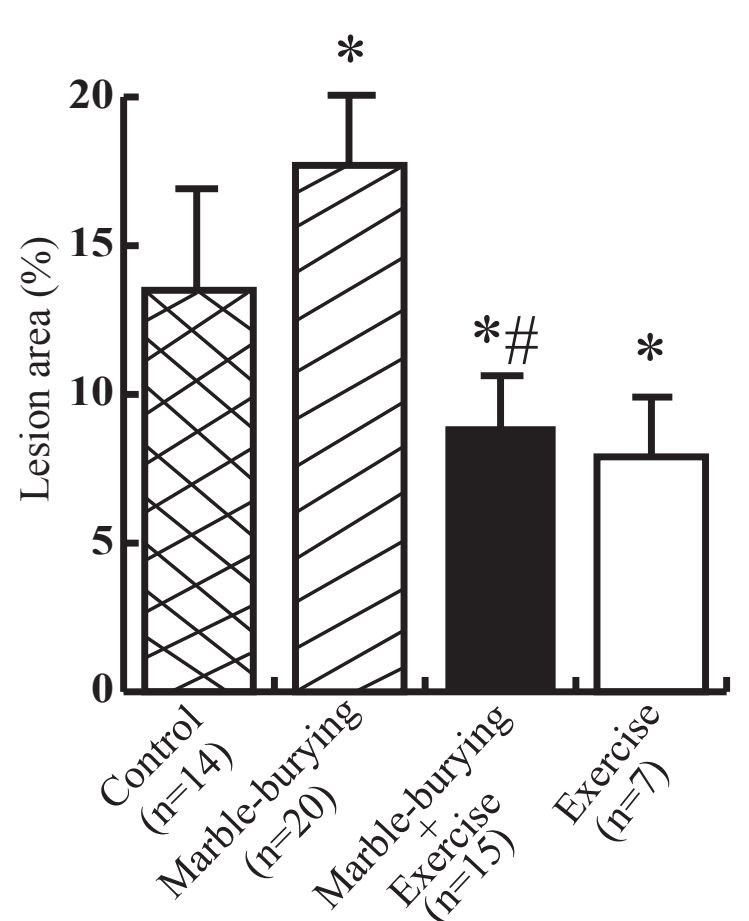

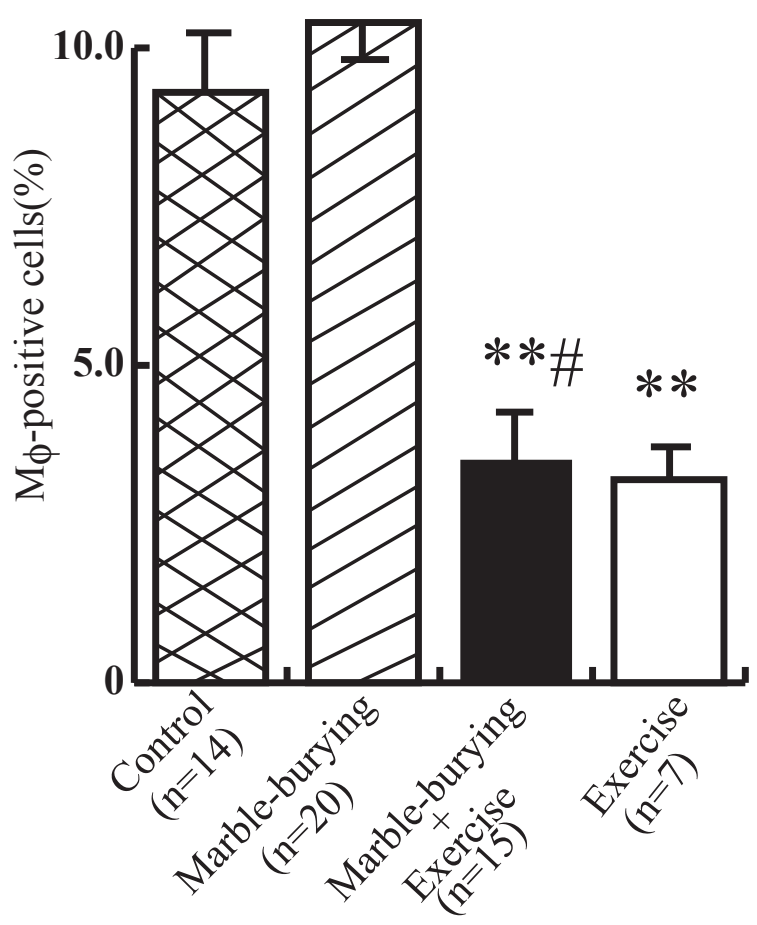


Figure 3.

(A) Control

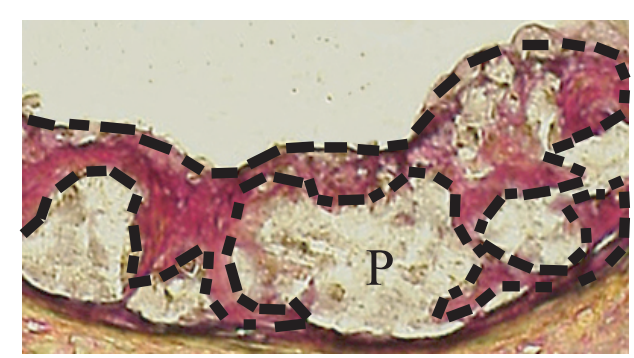

(C) Marble-burying + Exercise

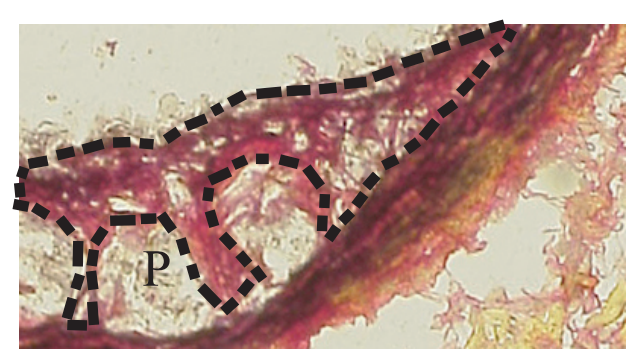

(B) Marble-burying

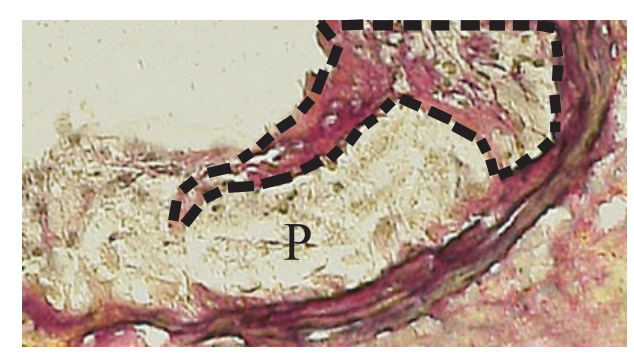

(D) Exercise

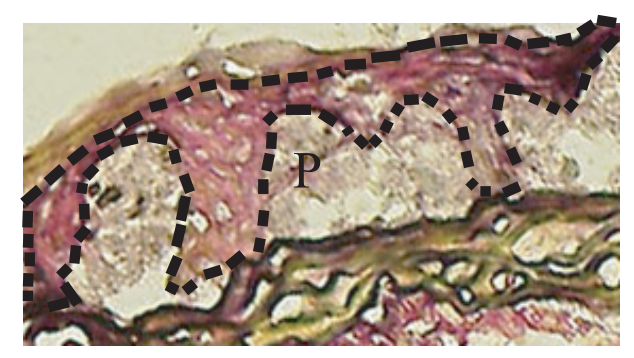

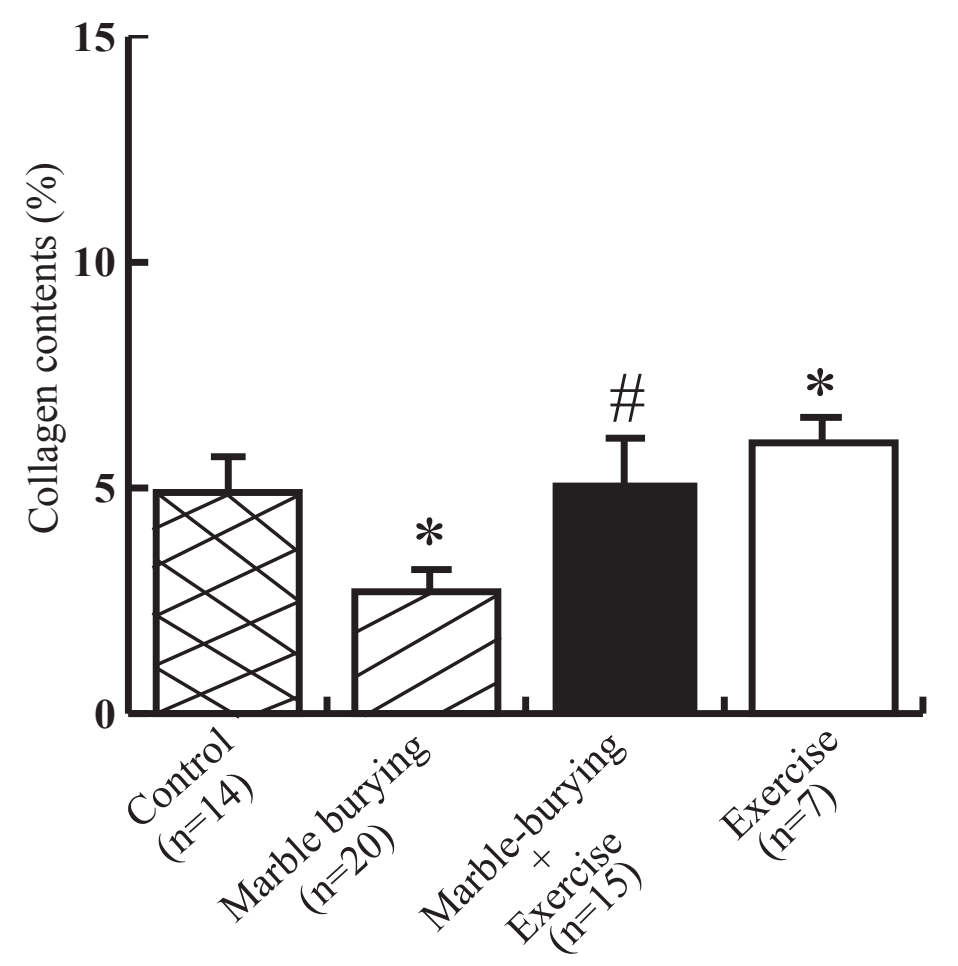


Figure 4.

\section{(A) Control}

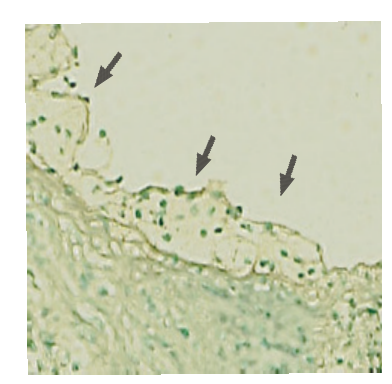

(B) Marble-burying

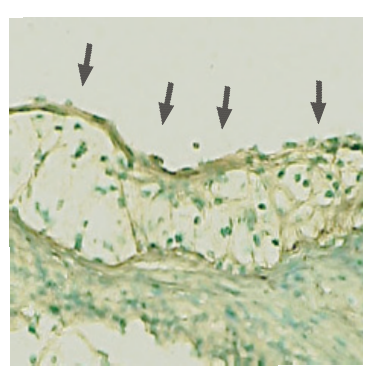

(C) Marble-burying + Exercise

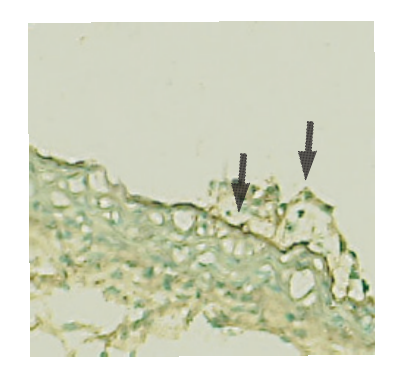

(D) Exercise

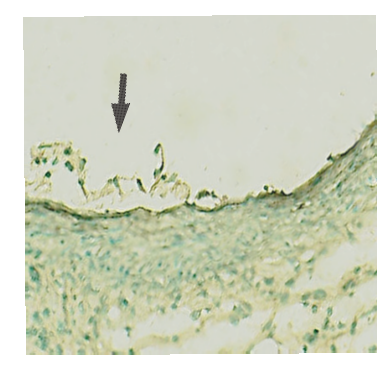


Figure 5.

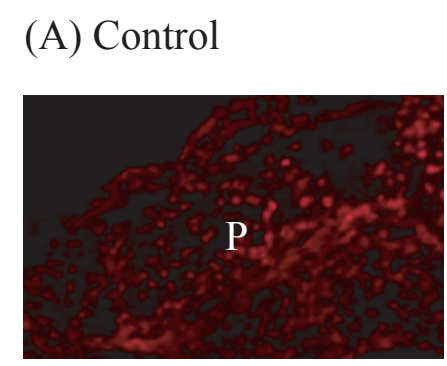

(C) Marble-burying + Exercise

(D) Exercise

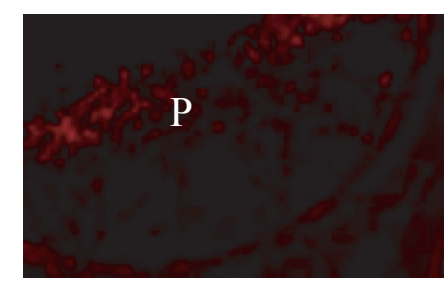

(B) Marble-burying

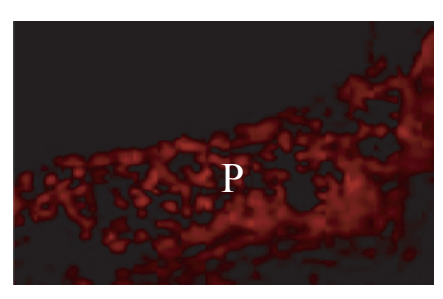

$\mathrm{P}$

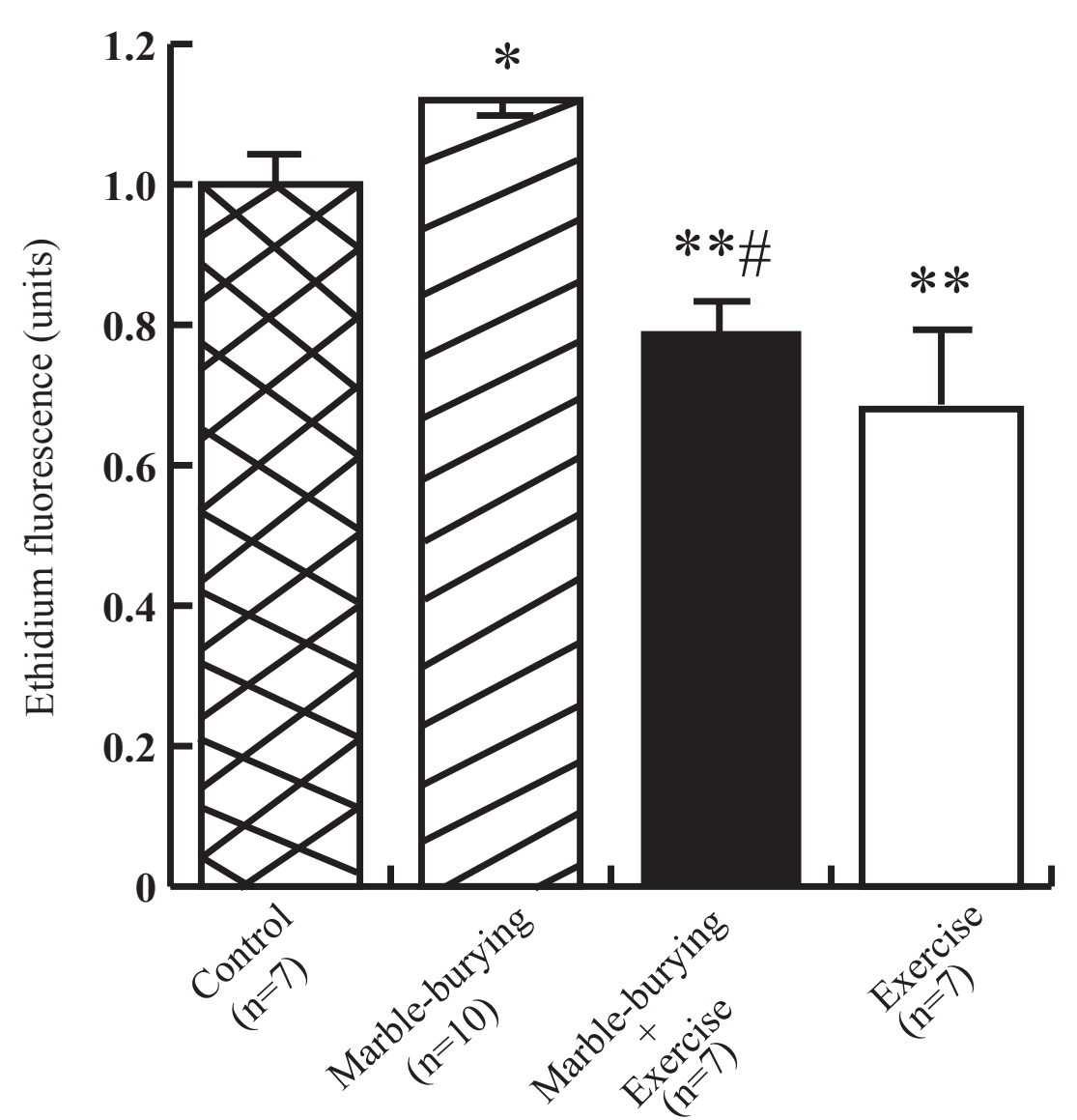


Figure 6.

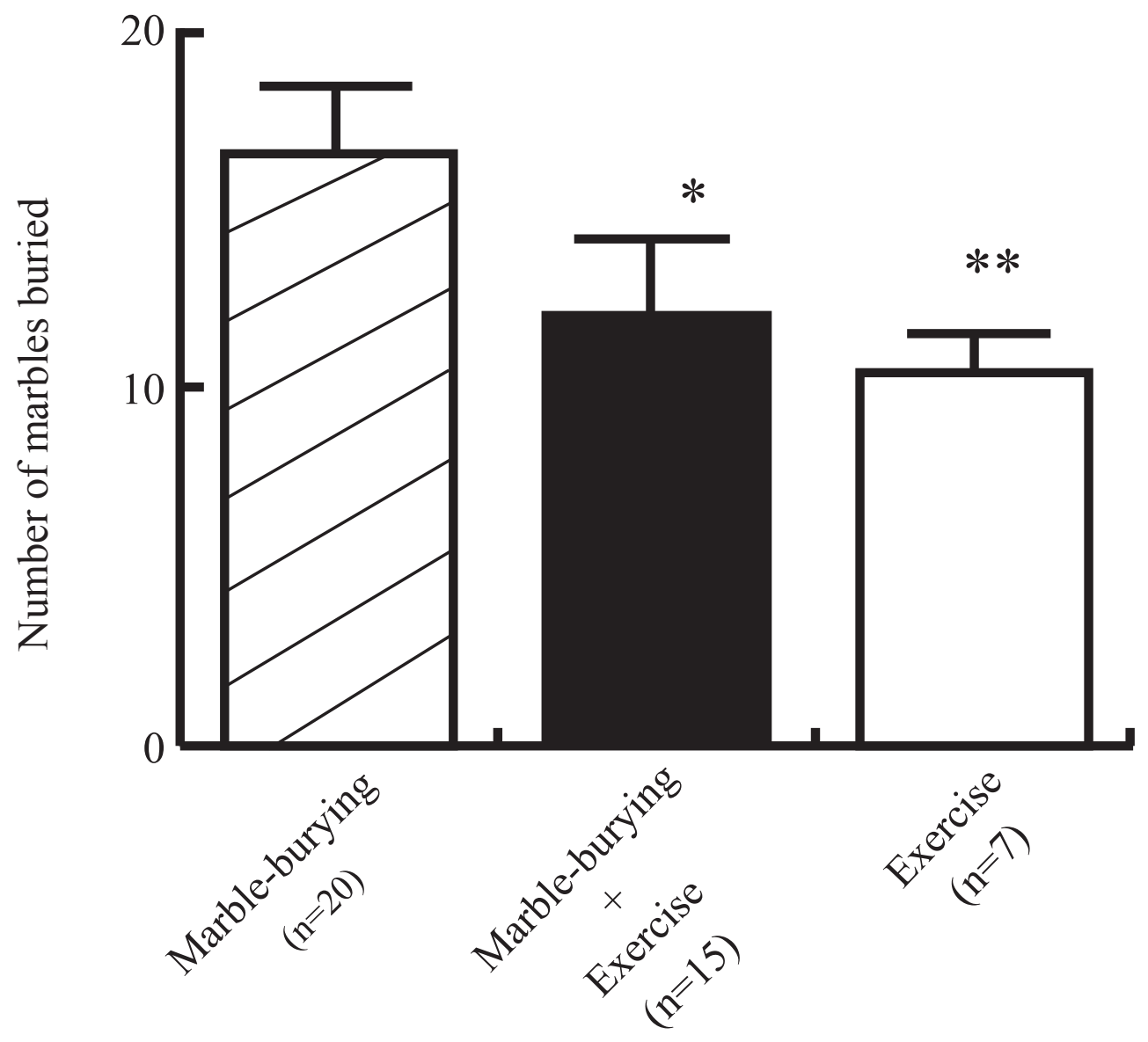


Table 1 Organ weights and lipid profiles

\begin{tabular}{|c|c|c|c|c|c|c|c|}
\hline & (n) & $\mathrm{BW}(\mathrm{g})$ & $\mathrm{HW}(\mathrm{g})$ & HW/BW(mg/g) & (n) & $\mathrm{TC}(\mathrm{mg} / \mathrm{dl})$ & $\mathrm{TG}(\mathrm{mg} / \mathrm{dl})$ \\
\hline Control & 14 & $31.5 \pm 5.5$ & $0.19 \pm 0.04$ & $6.03 \pm 0.65$ & 6 & $1307 \pm 273$ & $54.5 \pm 28.4$ \\
\hline Marble-burying & 20 & $30.7 \pm 6.2$ & $0.21 \pm 0.04$ & $6.84 \pm 0.63$ & 6 & $1187 \pm 283$ & $68.0 \pm 48.3$ \\
\hline $\begin{array}{l}\text { Marble-burying }+ \\
\text { Exercise }\end{array}$ & 15 & $31.7 \pm 4.9$ & $0.20 \pm 0.04$ & $6.31 \pm 0.60$ & 6 & $1586 \pm 304$ & $52.5 \pm 23.1$ \\
\hline Exercise & 7 & $31.7 \pm 6.0$ & $0.19 \pm 0.05$ & $5.99 \pm 0.71$ & 5 & $1233 \pm 249$ & $60.4 \pm 34.4$ \\
\hline
\end{tabular}

BW=body weight, $\mathrm{HW}=$ heart weight, $\mathrm{TC}=$ total cholesterol, $\mathrm{TG}=$ triglyceride . 
Table 2 Lesion area

\begin{tabular}{|c|c|c|c|c|c|}
\hline & (n) & Lesion area, $\mu \mathrm{m}^{2}(\%)$ & Collagen contents, $\mu \mathrm{m}^{2}(\%)$ & $\mathrm{M} \phi$-positive cells (\%) & Ethidium fluorescence (units) \\
\hline Control & 14 & $105.30 \pm 39.0 \times 10^{3}(13.5 \pm 5.0)$ & $38.22 \pm 10.14 \times 10^{3}(4.9 \pm 1.3)$ & $9.3 \pm 2.7$ & $1.00 \pm 0.07(\mathrm{n}=7)$ \\
\hline Marble-burying & 20 & $138.06 \pm 25.74 \times 10^{3}(17.7 \pm 3.3)^{*}$ & $21.06 \pm 7.8 \times 10^{3}(2.7 \pm 1.0)^{*}$ & $10.4 \pm 3.0$ & $1.12 \pm 0.05^{*}(\mathrm{n}=10)$ \\
\hline $\begin{array}{c}\text { Marble-burying } \\
+ \text { Exercise }\end{array}$ & 15 & $69.42 \pm 19.50 \times 10^{3}(8.9 \pm 2.5)^{* \#}$ & $39.78 \pm 17.94 \times 10^{3}(5.1 \pm 2.3) \#$ & $3.5 \pm 2.3 * * \#$ & $0.79 \pm 0.07 * * \#(\mathrm{n}=7)$ \\
\hline Exercise & 7 & $61.62 \pm 15.60 \times 10^{3}(7.9 \pm 2.0)^{*}$ & $46.80 \pm 10.92 \times 10^{3}(6.0 \pm 1.4)^{*}$ & $3.2 \pm 3.0 * *$ & $0.68 \pm 0.10 * *(\mathrm{n}=7)$ \\
\hline
\end{tabular}

$(\mathrm{Mn} \pm \mathrm{SD})$

$\mathrm{M} \phi=$ macrophage.

$* \mathrm{P}<0.05, * * \mathrm{P}<0.01$ vs Control group. \# $\mathrm{P}<0.01$ vs Marble-burying group. 
Table 3 Lipid profiles

\begin{tabular}{lccc}
\hline & (n) & TC $(\mathrm{mg} / \mathrm{dl})$ & TG $(\mathrm{mg} / \mathrm{dl})$ \\
\hline Control & 6 & $1307 \pm 273$ & $54.5 \pm 28.4$ \\
Marble-burying & 6 & $1187 \pm 283$ & $68.0 \pm 48.3$ \\
Marble-burying + Exercise & 6 & $1586 \pm 304$ & $52.5 \pm 23.1$ \\
& 5 & $1233 \pm 249$ & $60.4 \pm 34.4$ \\
Exercise & 5 & & $(\mathrm{Mn} \pm \mathrm{SD})$
\end{tabular}

$\mathrm{TC}=$ total cholesterol, $\mathrm{TG}=$ triglyceride. 